\title{
The best workers. La imagen en la prensa estadounidense de los obreros gallegos en el canal de Panamá (1906- 1915)
}

\section{The best workers. The image in the us press of the gallician labourers in the Panama Canal (1906-1915)}

\author{
Alberto Pena-Rodríguez. Universidad de Vigo. España. \\ alberto@uvigo.es \\ $[\mathrm{CV}] \odot \mathrm{G}$ \\ David Formoso. Universidad de Vigo. España. \\ davidformoso@uvigo.es \\ $[\underline{\mathrm{CV}}] \odot \mathrm{G}$
}

Cómo citar este artículo / Referencia normalizada

Pena-Rodríguez, A. y Formoso, D. (2021). The best workers. La imagen en la prensa estadounidense de los obreros gallegos en el canal de Panamá (1906-1915). Revista Latina de Comunicación Social, 79, 89-111 https://www.doi.org/10.4185/RLCS-2021-1490

\begin{abstract}
RESUMEN
Este trabajo analiza la imagen de los obreros gallegos que participaron en la construcción del Canal de Panamá en la prensa de Estados Unidos. El objetivo principal es averiguar cuáles son los aspectos más relevantes de su caracterización étnica y en qué medida los periódicos norteamericanos reprodujeron o se apartaron de los estereotipos que había de los gallegos, tanto en España como en Latinoamérica. Y, al mismo tiempo, indagar las causas de estas caracterizaciones étnicas y posibles intereses propagandísticos, ya que la construcción de esta vía marítima surgió, no sólo por una necesidad de comunicación entre dos océanos, sino también como un proyecto de imagen de este país como nueva potencia mundial. Por medio de técnicas cualitativas y una amplia selección de noticias y reportajes sobre el objeto de estudio, se establecen varias categorías de análisis que demuestran que el perfil de los gallegos que representaron la mayoría de los periódicos intentaba evitar el estigma negativo que, en general, se atribuía a los españoles tras el enfrentamiento militar en 1898, como gente atrasada y holgazana. Influida por una campaña dirigida por la empresa constructora del Canal y el gobierno norteamericano, algunos periódicos estadounidenses reconocieron en los inmigrantes gallegos amplias cualidades laborales, con el fin de evitar que la opinión pública los relacionase con la imagen decadente de España que la propaganda antiespañola había difundido a finales del siglo XIX.
\end{abstract}

PALABRAS CLAVE: Inmigración Gallega; Canal Panamá; Prensa; Estados Unidos; Propaganda; Relaciones Públicas 


\begin{abstract}
This paper analyzes the image of the Galician workers who participated in the construction of the Panama Canal in the United States press. The main objective is to find out what are the most relevant aspects of their ethnic characterization and to what extent the American newspapers reproduced or departed from the stereotypes of Galicians, both in Spain and Latin America. And, at the same time, to investigate the causes of these ethnic characterizations and possible propagandistic interests, since the construction of this seaway arose not only out of a need for communication between two oceans, but also as a project for the image of this country as a new world power. Through qualitative techniques and a wide selection of news and reports on the object of study, several categories of analysis are established that show that the profile of Galicians who represented most newspapers tried to avoid the negative stigma that, in general, it was attributed to the Spaniards after the military confrontation in 1898, as backward and lazy people. Influenced by a campaign led by the Canal construction company and the US government, some American newspapers recognized Galician immigrants with broad work qualities, in order to prevent public opinion from relating them to the decadent image of Spain that anti-Spanish propaganda had spread in the late nineteenth century.
\end{abstract}

Keywords: Galician Emigration; Panama Canal; Press; United States; Propaganda; Public Relations

\title{
CONTENIDO
}

1. Introducción. 2. Objetivos. 3. Metodología. 4. Discusión de resultados. 5. Conclusiones. 6. Referencias.

\section{Introducción}

La emigración gallega a Panamá para trabajar en la construcción del canal interoceánico fue un fenómeno de aluvión limitado a un espacio temporal de 8 años de duración y, por su naturaleza estacional, no tuvo una continuidad significativa en el tiempo, lo que la diferencia de las principales corrientes migratorias que se desarrollaron en el período de las grandes migraciones a América, entre 1870 y 1930 (Moya, 1998, p. 45, Moya y McKeown, 2011, p. 17), comparable en algunos aspectos a fenómenos modernos (Llevot Cavet y López Teulón, 2017). Desde el inicio de 1906 hasta el final de 1908, partieron de manera legal para el país centroamericano 8.298 españoles $^{1}$ de los cuales 5.983 eran gallegos, el 72,7 por ciento, según los cálculos de Juan Manuel Pérez (2007, p. 105). De acuerdo con este autor, a esta cifra habría que añadir unos 3.000 más que, tras la prohibición gubernamental de mediados de noviembre de 1908, lo hicieron de forma ilegal desde diferentes puertos Francia y España, vía Costa Rica y Cuba, hasta finales de 1912, lo que suma una cifra total de 11.298, de los cuales, de mantenerse el porcentaje anterior, en torno a 8.000 procederían de Galicia. Se debe sumar otro contingente, sin cifras conocidas, de emigrantes clandestinos durante los tres primeros años de las obras, conformado por los menores de veinticinco años, edad mínima autorizada por el gobierno español para poder emigrar por estar en edad militar.

La necesidad de obreros era apremiante, de manera que la empresa encargada de la construcción, la Comisión del Canal Ístmico ${ }^{2}$ (en adelante CCI) fue cómplice activa de esta emigración laboral ilícita, pues abonaba veinticinco pesetas por persona embarcada con destino a Panamá al consignatario vigués Estanislao Durán, quien alegó que parte de esa cantidad se destinaba a sobornar a las autoridades (Park, 1906, 17 de septiembre). En enero de 1906, los responsables de la CCI iniciaron la captación de trabajadores españoles en Cuba y, una vez comprobada su eficiencia, continuaron en

\footnotetext{
${ }^{1}$ Cifra publicada por la Comisión del Canal Ístmico (CCI) en su periódico oficial The Canal Record (1914, p. 3), cifra a la que habría que añadir 500 más llevados desde Cuba, casi todos gallegos.

${ }^{2}$ Empresa pública dependiente del departamento de Guerra de Estados Unidos.
} 
España con desapego a los principios de liderazgo empresarial (Checa Calderón y Rodríguez Caguana, 2017; Santacruz Espinoza et al, 2020) hasta mediados de noviembre de 1908, cuando el gobierno presidido por Antonio Maura prohibió el reclutamiento. A partir de esa fecha, el número de trabajadores españoles fue disminuyendo poco a poco hasta 1912, cuando se redujo sensiblemente la carga de trabajo. Sólo unos pocos inmigrantes más llegaron antes del final de la obra, en agosto de 1914.

Teniendo en cuenta la influencia de la prensa en la construcción de las identidades (Máiz, 2003, p. 106) en ausencia de medios más recientes (Marcos Ramos et al, 2019; Vaquerizo Domínguez, 2019) aunque no de vicios más recientes (Barrientos-Báez et al, 2018) el objeto de estudio lo constituyen las informaciones publicadas sobre los trabajadores gallegos en el Canal de Panamá en una amplia muestra de periódicos estadounidenses entre 1906, cuando se inicia el reclutamiento de obreros gallegos, y 1915, poco después de finalizadas las obras, aunque es en los dos primeros años cuando se concentra el mayor número de noticias sobre el tema, lo que hoy constituyes una actuación comunicativa sobre el patrimonio (Walls Ramírez, 2020). Frente a la cobertura de la prensa española, que adoptó, en general, una actitud muy crítica con las condiciones de trabajo en el Canal y el trato recibido por los obreros españoles (Formoso y Pena-Rodríguez, 2018, p. 39), el discurso de los medios de información norteamericanos, influidos por el rol de su país como nueva potencia colonial y administrador del istmo panameño, pudo tener un enfoque distinto. Sobre todo, si el análisis se hace en el marco de las diferencias entre los modelos políticos de España y Estados Unidos y sus relaciones bilaterales.

En aquellos años la prensa norteamericana en su conjunto era un negocio floreciente al margen de los poderes públicos, con sus luces y sus sombras. Como un hecho relevante en su desarrollo, cabe destacar el nacimiento a principios de siglo XX del moderno periodismo de investigación, conocido por el peyorativo nombre de Muckraking, en el que destacó el novelista Upton Sinclair y los periodistas Ida Tarbell, Lincoln Steffens, Jacob Riis, Nellie Bly, Charles Edward Russel y Edwin Makham (Feldstein, 2006, p. 107). Un fenómeno que convivió con el amarillismo de las cabeceras de William R. Hearst, quien anteponía las ventas a la ética periodística (Procter 1998). El número de diarios se dobló entre 1892 y 1914, pasando de 1.650 a 2.250 y, si se incluyen todas, en 1900 alcanza los 5.500 títulos. Esta magnitud del negocio de la prensa propició dos efectos opuestos desde el punto de la calidad periodística: por un lado, facilitó su independencia efectiva de los poderes públicos, pero al mismo tiempo, con frecuencia, la ambición de aumentar el volumen de facturación se imponía a la línea informativa más seria de los periódicos, abusando del sensacionalismo (Wagenknecht, 1982, p. 195), como ha resultado tristemente común (Martínez O'Farrill, 2019 y 2018).

\section{Objetivos}

En el marco de análisis de este fenómeno migratorio singular, y con el espíritu sugerido por Niño González y Linares Herrera (2020) el objetivo principal de este trabajo, similarmente a otros estudios de tipo similar (Soto Lara et al, 2019) es estudiar los rasgos étnicos y culturales más relevantes de los obreros gallegos que trabajaron en el Canal y su representación en la prensa de Estados Unidos, dentro del contexto general de la emigración gallega a América, donde se reprodujeron los estereotipos peninsulares sobre los gallegos en sus destinos migratorios, particularmente en Argentina (Núñez-Seixas, 2015 y 2017, Lojo, 2017, Farías, 2010; Guidotti, Lojo y Farías, 2008) y Cuba (Vidal-Rodríguez, 2003 y 2005).

Como objetivos no menos importantes, se analizará en primer lugar, si la prensa norteamericana asumió los estereotipos negativos sobre los gallegos existentes en Iberoamérica o, por el contrario, 
dada la necesidad perentoria de mano de obra para la construcción del canal, se divulgó una imagen distinta, menos peyorativa o incluso positiva sobre ellos y, al mismo tiempo, indagar acerca de cuáles pudieron ser las causas. En segundo lugar, se pretende averiguar en qué medida la identidad étnica de los obreros gallegos pervivió y se manifestó en la Zona del canal, de manera diferente o no, a la de los demás españoles, y si esta marca diferencial tuvo un reflejo en los periódicos más relevantes de Estados Unidos.

El trabajo parte de la hipótesis de que, frente a la cobertura de la prensa española, que adoptó, en general, una actitud muy crítica con las condiciones de trabajo en el Canal y el trato recibido por los obreros españoles (Formoso y Pena-Rodríguez, 2018), el discurso de los medios de información norteamericanos, influidos por el rol de su país como nueva potencia colonial y administrador del istmo panameño, pudo tener un enfoque muy distinto. Principalmente, si el análisis se hace en el contexto de las notorias diferencias entre los modelos políticos de España y Estados Unidos.

Partiendo de este encuadre, se plantean varios interrogantes a los que se intentará responder:

a) ¿Cuáles fueron los rasgos principales de la representación los obreros gallegos en el canal en la prensa norteamericana?

b) ¿Cuál era su arquetipo étnico?, ¿hubo una distinción con respecto al resto de los españoles?, ¿si la hubo, en qué consistió?

c) ¿La imagen de los obreros gallegos en el discurso periodístico de Estados Unidos era un reflejo del estigma o los estereotipos sociales asociados a los inmigrantes de Galicia en Latinoamérica?

d) ¿Su imagen general era positiva o negativa? y

e) ¿El gobierno norteamericano desarrolló alguna estrategia o campaña de Relaciones Públicas en relación con su gestión de la construcción del istmo que afectase a la percepción de los obreros gallegos?

\section{Metodología}

Los medios de comunicación han tenido -y tienen- un papel capital en la reproducción, construcción, distorsión (e, incluso, disolución en el marco de una sociedad interétnica o intercultural) de una identidad colectiva, sea una comunidad étnica, religiosa, nacional (o idea de nación) o de cualquier otra naturaleza. Los conceptos, rituales tradicionales y símbolos, elaborados por las élites culturales, políticas y económicas, cuando se divulgan a través de determinados formatos y códigos narrativos mediáticos lo hacen siguiendo unos marcos interpretativos, una perspectiva desde la que se valoran y seleccionan los hechos (la agenda de los medios), así como los aspectos que encuadran los mismos en un contexto concreto (el framing) (Ardèvol-Abreu, 2015). Un proceso en el que las formas del lenguaje y la mirada basada en valores o prejuicios culturales o ideológicos son un medio que puede determinar la representación, la percepción y la creación de la realidad, que los periodistas van ajustando en función del feedback de los editores y del público (Rodrigo-Alsina y Medina, 2009, p. 29).

Para estudiar la prensa norteamericana se han aplicado técnicas cualitativas basadas en el análisis del discurso y de contenido, que han servido para interpretar la imagen de los inmigrantes gallegos atendiendo a las siguientes categorías o encuadres de análisis:

1. La existencia (o no) de estereotipos sobre los gallegos en los periódicos de referencia de Estados Unidos.

2. Su representación étnica en comparación con los españoles en el marco de las complejas relaciones hispano-norteamericanas.

3. La valoración de su desempeño de su laboral en las obras de canal de Panamá. 
4. Su caracterización arquetípica desde una perspectiva racial y cultural.

La recopilación de fuentes hemerográficas se ha realizado a través del catálogo de la Biblioteca del Congreso de Estados Unidos y de la bases de datos Newspaper Archive, complementada con la consulta de los repositorios de los grandes periódicos de la época: The Washington Post, el de mayor circulación en la capital, y The New York Times, que entonces apostó por un periodismo riguroso en contraste con los amarillistas New York World, de Joseph Pulitzer, New York Journal, de William Hearst, y el desaparecido The Outlook, que en la primera década del siglo XX era, junto a The Independent, un semanario de los más influyentes (Wagenknecht, 1982, p. 216).

Se han realizado búsquedas generales a partir de términos específicos como "Panama Canal", "Galician immigrants", "Gallegos", "Galicia" o "Spanish Immigrants", que han permitido localizar hasta 42 cabeceras que mencionaron (de algún modo) a los obreros gallegos del canal, catorce de las cuales se limitaron a reproducir piezas difundidas previamente por otros periódicos. Este estudio centra su análisis, principalmente, en las informaciones o artículos más extensos y relevantes publicados por la prensa estadounidense. Los periódicos que se refirieron a los obreros gallegos en el canal son los siguientes: The New York Times, New York Tribune, The News-Herald, Tazewell Republican, The Holt County Sentinel, Coffeyville Daily Record, The Louisburg Herald, Suburbanite Economist, The Burlington Free Press, The Portsmouth Herald, The Washington Post, The Outlook, The Washington Herald, San Francisco Call, Oakland Tribune, The Outlook, The Charlotte News, The Daily Telegram, Boston Evening Transcript, The New York Times, The Sun, The Canal Record, The Pittsburgh Press, The Washington Herald, The Wichita Daily Eagle, The Boston Globe, Dayton Daily News y St. Louis Post-Dispatch.

La participación de los obreros españoles en la construcción del canal ístmico fue estudiada previamente en diversos trabajos, entre los que destacan autores como Juan Manuel Pérez, cuya monografía sobre los inmigrantes gallegos del canal (2007) se centra en las cifras y procedencias de la emigración gallega y su difícil integración en la vida y las condiciones laborales impuestas por las autoridades norteamericanas. Greene (2004 y 2011) investigó la ubicación de los braceros españoles en un sistema racista. Un tema que fue abordado también por Yolanda Marco Serra (1997 y 2012), que además describió el tratamiento informativo de los periódicos españoles El Liberal y El Socialista, que se complementa con un trabajo de los autores de este artículo (2018), en el que se analiza de forma extensa el fenómeno de la imagen de la emigración gallega en la prensa española.

En este marco de análisis, este artículo propone un objeto de estudio novedoso, que pretende aproximarse de un modo interdisciplinar y transversal al conocimiento de la historia de la emigración gallega a América a través de su imagen en la prensa norteamericana a principios del siglo XX.

\section{Discusión de resultados}

\subsection{El estigma del inmigrante. Identidad y estereotipos de los gallegos en América}

Para poner en contexto la representación que de los obreros gallegos en el canal de Panamá hizo la prensa norteamericana, es necesario referirse a la identidad de los inmigrantes procedentes de Galicia y su imagen social en Iberoamérica ha ido evolucionando, aunque su representación mediática o popular siempre ha mostrado una tendencia hacia su estigmatización cultural. A principios de siglo XX, Galicia era el territorio con la etnicidad diferenciada más extensa y homogénea de toda España, aunque esta circunstancia operó como un marcador social negativo (Beramendi, 2002, p. 121). 
El origen de este estigma se sitúa, principalmente, en el Siglo de Oro español, donde confluyeron tres factores fundamentales para su construcción social: una identidad fuerte, acentuada por el uso de una lengua propia (el gallego), una procedencia rural analfabeta y una ocupación laboral no cualificada en la capital de reino, en Madrid, a donde muchos emigraron. La literatura, en particular el teatro popular, contribuyó a difundir, consolidar y exagerar estos rasgos. Se popularizó así una imagen despectiva de los gallegos, similar al desprecio de los ingleses por los irlandeses, o de los franceses por los gascones (Murado, 2008, p. 73).

Pero no todas las descripciones literarias estigmatizaban a los gallegos con un lenguaje ofensivo. En la selección de fragmentos literarios en los que aparecen Galicia y los gallegos, elaborada por Teijeiro Fuentes (1996, p. 203), a los atributos negativos de deslealtad, ingenuidad (en contexto negativo), tacañería, lascivia, falta de compromiso religioso, fealdad, suciedad o desaliño, se contraponían, aunque en muy menor medida, otros como belleza, bondad, sinceridad, de ambición comedida, nobleza y valentía, estos dos últimos generalmente referidos a personajes poderosos, con frecuencia nobles gallegos con cargos en la Corte. La categorización social, pues, imponía en general un estigma que colocaba a los gallegos en un lugar inferior frente a otras identidades españolas, como la castellana, vasca, catalana o andaluza.

Con el paso del tiempo, el estereotipo especialmente infamante se fue suavizando, tanto en España como en Europa. Esto es al menos lo que se desprende del compendio de sentencias sobre los gallegos y Galicia, recogidas por Alonso Montero (1974) y en las enciclopedias alemanas analizadas por Johannes Kramer (1997, p. 152). De los tópicos grotescos del Siglo de Oro que aparecen en el manual de Johan H. Zedler, editado en la década de los treinta del siglo XVIII, se pasa a una mirada positiva en el diccionario de Friedrich A. Brockhaus, publicado en 1884 y 1908, que los describe más parecidos a los portugueses que a los españoles, fuertes, vigorosos, serios, laboriosos, honestos, respetables y ahorradores.

Los estereotipos de los gallegos llegaron a Hispanoamérica ya en tiempos del imperio español a través de la producción literaria y, sobre todo, por la inmigración gallega del siglo XIX, procedente de entornos agrarios, carente de una socialización de hábitos urbanos, lo que favoreció nuevamente su estigmatización. En Argentina, los tópicos negativos provenientes de la Península evolucionaron y se revitalizaron en determinados momentos históricos (Moya, 2008). Entre ellos, cabe destacar el proceso de independencia, cuando el gentilicio gallego pasó a aplicarse a todos los españoles como un desprecio, lo mismo que ocurrió con ocasión de la Guerra del Pacífico que enfrentó a España con Perú, Chile y Ecuador (Núñez-Seixas, 2015, p. 218). Otros motivos de su revitalización fueron la reproducción, a mediados del siglo XIX, por parte de la prensa argentina, de los chistes publicados en Madrid sobre gallegos, o los conflictos obreros en los que se significaron, que propiciaron que el gentilicio se convirtiese en un insulto o palabra menospreciativa, lo que hizo a muchos renegar de su origen (Núñez-Seixas, 2013, p. 26).

Como en el Siglo de Oro, en Argentina y en otros destinos de la emigración gallega, los que desempeñaron cargos, profesiones cualificadas e intelectuales quedaron al margen del estigma negativo. Los demás podían ser objeto de referencias ofensivas o positivas, dependiendo del contexto. Las virtudes más comunes atribuidas a los gallegos eran la honradez, laboriosidad e integridad moral (Lojo, 2016, p. 3). En Cuba, donde la inmigración gallega dejó una impronta cultural en la sociedad local, los estereotipos negativos se atenuaron tras la independencia. Con anterioridad, el término gallego, que significaba cochino para los cubanos, se extendió a todos los españoles en su sentido peyorativo (González-Suárez, 2005, p. 207). 
Tras la ocupación norteamericana, a los nuevos administradores les preocupó la escasez de mano de obra en los planes de desarrollo de la economía de Cuba. Una necesidad perentoria para la industria azucarera desde la abolición de la esclavitud, que se agravó con la pérdida de centenares de vidas durante la guerra de independencia (Sánchez-Cobo, 2008, p. 63). La demanda también creció con la mejora y construcción de infraestructuras, poniendo en valor a los inmigrantes españoles frente a la mano de obra cubana.

La guía para gente de negocios de William J. Clarck destacó la laboriosidad e iniciativa comercial de los campesinos gallegos y catalanes, además de su resistencia y abnegación (VidalRodríguez, 2003, p. 37). En particular, las élites de la colonia gallega esquivaron la simbolización negativa, cultivando siempre una gran proximidad al poder de turno. En los dos períodos de administración norteamericana de la isla, mantuvieron con ellos lazos estrechos (Iglesias-Cruz, 2012, p. 366), incluso mostrando a veces su apoyo a la integración de Cuba en Estados Unidos y utilizando su poder económico para que la prensa local dejara de criticar a las fuerzas ocupantes (Cuadriello, 2004, p. 209).

De hecho, el Centro Gallego en La Habana colaboró con las autoridades norteamericanas en mejorar la imagen de su gestión laboral en el Canal de Panamá. En el solemne acto de colocación de la primera piedra del nuevo edificio de esta institución, al que acudió el gobernador, Charles Magoon, que antes lo había sido de la Zona del Canal, el presidente de la entidad gallega le presentó personalmente a los complacientes comisionados que informarían sobre la lamentable situación de los trabajadores españoles en la isla, la mayoría gallegos (Magoon, 1907, 12 de diciembre). Un asunto denunciado, además, por la prensa española y la National Civic Federation (NCF), a pesar de ser esta una entidad creada y financiada por varios trust norteamericanos para restar influencia a los sindicatos de obreros (Rothbard, 1996, p. 210). El informe que elaboraron Guerrero y Lorente (1908) fue muy favorable a los intereses gubernamentales de Estados Unidos al señalar únicamente pequeños problemas, eludiendo la mala situación laboral y sanitaria (Navas, 1979, p. 141).

En la Zona del Canal, los cuadros medios de la CCI solían diferenciar a los gallegos de los demás españoles, como atestiguan los informes del jefe de policía de la Zona, Edward Sandrad (1907, febrero-marzo). Sin embargo, mientras los gallegos mantenían una clara identidad étnica en Cuba, en Panamá adoptaron una más permeable a las circunstancias, prevaleciendo en el ámbito público su marca española. La situación allí era más hostil debido a las enormes diferencias culturales, idiomáticas, sociales y laborales, lo que estimuló un sentimiento de solidaridad entre españoles de diferentes regiones. En su enfoque racista de la organización laboral, la CCI encuadró a los trabajadores de origen ibérico en un estadio intermedio y fluido entre blancos (la mayoría norteamericanos) y negros ${ }^{3}$, facilitando así, en diferentes circunstancias, el manejo de sus propios prejuicios raciales para fomentar la competencia y rivalidades con otras etnias ${ }^{4}$ (Greene, 2011, p. 218). La reivindicación de su identidad de los inmigrantes gallegos se centró en que se les considerase obreros blancos, ya que, en su percepción, implicaba un estatus y derechos inherentes a esa cualidad, además de los reconocidos en las promesas de las condiciones laborales. Estas aspiraciones provocaron huelgas y otras protestas que sirvieron para que los españoles se aglutinaran y dejaran de lado sus identidades regionales (Greene, 2004, p. 79).

\footnotetext{
${ }^{3}$ En el contexto de la fantasía de la pureza racial de la época, la mentalidad anglo-americana situaba a los españoles en una raza mixta, blancos moralmente ennegrecidos o híbridos (véase De Guzmán, 2005, pp. 23-24).

${ }^{4}$ Esta estrategia de dividir y hacer competir a los trabajadores inmigrantes de diferentes etnias o naciones también la practicaban entonces otras empresas en Estados Unidos. Fue el caso de la Graselli Chemical Company de Virgina (Varela-Lago, 2008, pp. 156-157).
} 
En esta estrategia de cohesión identitaria colaboraron también los dirigentes anarquistas (Shaffer, 2011, p. 13), que preferían superar los orígenes étnicos defendiendo una identidad proletaria universalista, propia de la mentalidad obrerista de la época. Entre los más activos se encontraban algunos gallegos como Aquilino López, Bernardo Pérez, José Novo y Juan Lóuzara (apodado Rudolf Lone) (Alonso, 2013, p. 51), que se agrupaban en torno al periódico El Único. La continua llegada de inmigrantes y la reemigración de los que ya estaban en la Zona del Canal fue otra de las causas que debilitó la afirmación de la identidad gallega, expresada por los inmigrantes gallegos principalmente en sus espacios de ocio, en torno a fondas regentadas por familias procedentes de Galicia, donde pasaban parte de sus horas libres y se relacionaban en un ambiente endogámico (Pérez, 2007, p. 197).

\subsection{Gallegos antes que antillanos. La contratación de obreros para el Canal}

Tras el cuestionamiento del proyecto del Canal de Panamá por el congreso y una parte de la prensa ${ }^{5}$ de Estados Unidos debido a la pésima gestión de la primera CCI (Araúz y Pizzurno, 2003, p. 108; Mack, 1978, p. 469), a finales de 1905 el gobierno norteamericano realizó un reclutamiento urgente de obreros para avanzar en su construcción. El retraso de las obras era un contratiempo importante en la política del presidente Theodore Roosevelt, que compartía la teoría del poder marítimo de Alfred Mahan (Baqués-Quesada 2018, p. 114), quien consideraba la vía ístmica como un objetivo estratégico. Su realización era también una gran oportunidad propagandística de demostrar al mundo la superioridad y eficacia de la tecnología estadounidense, así como su liderazgo político (Greene, 2011, p. 37), favoreciendo no sólo la imagen exterior del país, sino también el prestigio interior del gobierno federal ante sus ciudadanos, en el marco de una política centralizadora frente a los estados federados (Missal, 2009, p. 54).

Por estas razones, el aspecto laboral de la construcción del canal se convirtió para el gobierno norteamericano y la CCI en uno de los prioritarios ante la escasez de mano de obra, pues ello podría deslucir la imagen del proyecto. Los nuevos ejecutivos e ingenieros del organismo encargado de llevarlo a cabo consideraron a finales de 1905 que era imprescindible contratar importantes contingentes de obreros eficientes. Consideraban que los antillanos, a los que veían como indolentes y carentes de motivación, monopolizaban la demanda de mano de obra de pico y pala en el istmo (Roediger y Esch 2012, p. 74). La solución propuesta inicialmente era emplear operarios chinos, a los que el ingeniero jefe John Stevens destacó como los mejores después de haber trabajado con ellos en la construcción de los ferrocarriles del oeste. Pese al apoyo de Roosevelt, su pretensión fracasó por la prohibición de la inmigración asiática de 1892 (Stevens, 1915, p. 213), la oposición de los sindicatos norteamericanos (Shonts broke... 1906, p.4) y, sobre todo, del gobierno chino (Chou, 2002 , p. 27). Se hacía necesaria entonces una buena alternativa a la opción asiática que ofreciese garantías ante la opinión pública.

Después de un intento fallido de reclutamiento entre los inmigrantes europeos que llegaban a Nueva York, la CCI orientó su búsqueda hacia Cuba, captando medio millar de inmigrantes españoles, casi todos originarios de Galicia (Pérez, 2007, p. 78) a los que los informes de los administradores norteamericanos definían como blancos manejables, dóciles ${ }^{6}$, buenos trabajadores, ambiciosos e inteligentes hasta cierto punto (Greene, 2011, p. 205; Vidal- Rodríguez, 2005, p. 333; Marco-Serra, 2012, p. 71). Cualidades que, a su juicio, los equiparaban a los asiáticos. El presidente de la CCI, T. Shonts $(1915$, p. 206), pretendía conseguir obreros de diferentes etnias y

\footnotetext{
${ }^{5}$ Una de las críticas más duras y controvertidas la publicó el periodista Poultney Bigelow (1906). Un amplio resumen de esta fue reproducido por varios periódicos.

${ }^{6}$ El estereotipo negativo de la docilidad de los gallegos fue reflejado también por el periódico español Madrid Científico, (Los esclavos modernos, 1907) que cita informes de la CCI.
} 
nacionalidades con el fin de fomentar la competencia entre ellos y, sobre todo, para acabar con el monopolio laboral de los antillanos. A fin de reforzar su propósito y desde una mentalidad racista, la CCI clasificó la mano de obra en listas de oro (básicamente trabajadores norteamericanos) y plata, con varias subclasificaciones, en las que encuadraba a los demás. De esta manera, se trataba de impedir un movimiento de solidaridad colectiva entre los asalariados para evitar los perjuicios de una eventual huelga general (Navas, 1979, p. 97).

Gran parte de los trabajadores gallegos reclutados en Cuba procedían de las obras públicas que Estados Unidos implementó tras la independencia cubana, un sector en el que trabajaban entonces muchos inmigrantes originarios de Galicia (Vidal-Rodríguez 2005, p. 145; Sánchez- Cobos 2008, p. 67). Sin embargo, la oposición de empresarios norteamericanos con inversiones en la isla a la contratación de obreros españoles, apoyados por el gobierno de La Habana (Greene, 2004, p. 82. Navas, 1979, p. 10), obligó a la CCI a buscar otras opciones; lo que la llevó hasta tierras gallegas, donde otras empresas de Estados Unidos ya habían contratado con anterioridad a trabajadores con buenos resultados. Una de ellas fue The Cuba Company, que, en otoño de 1901, había enviado a Galicia agentes que contrataron a 300 obreros para finalizar el ferrocarril central. En general, las grandes compañías norteamericanas prefirieron emplear a inmigrantes españoles antes que cubanos, y para las tareas más sacrificadas y peor pagadas, particularmente a los gallegos (VidalRodríguez, 2005, p. 231).

Para captar obreros en España sin incomodar al gobierno español, que no se oponía frontalmente pero tampoco quería ser visto como colaborador cuando la herida de la guerra de 1898 aún no había cicatrizado (Park, 1906, 14 de noviembre), el agente de la CCI Leroy Park estableció una oficina de contratación en París. Uno de sus lugares de reclutamiento en Galicia fueron las dependencias del consignatario de buques Estanislao Durán, en el puerto de Vigo. En casi dos años y medio, entre junio de 1906 y noviembre de 1908, consiguió embarcar 8.298 españoles con la complicidad de algunas autoridades y personalidades relevantes, como el ex presidente del gobierno Eugenio Montero Ríos (1906, 12 de julio), o las reticencias de su sucesor, Segismundo Moret (Varela-Lago, 2008, p. 193), como parte del juego político de la época y probablemente en el contexto de la negociación de un convenio comercial entre España y Estados Unidos. Leroy Park, sin embargo, se mantuvo siempre oculto a los ojos de la opinión pública española, a pesar de asistir en la ciudad gallega a algunos actos sociales, consiguió pasar ante la prensa local como un "capitalista norteamericano 7 ,"

\section{3. "North Spanish Blood". Los trabajadores gallegos en la prensa estadounidense}

Las primeras noticias de las contrataciones de obreros gallegos aparecen en periódicos de Estados Unidos ya a principios de 1906. Para el lector medio norteamericano, la palabra "gallego" posiblemente fuera desconocida $\mathrm{y}$, en el mejor de los casos, quizás estuviese al tanto del significado peyorativo que, desde la ocupación de $\mathrm{Cuba}$, se aplicaba en forma de sinécdoque a todos los españoles. Sin embargo, desde el punto de vista de la imagen, para las autoridades estadounidenses "gallego" era un gentilicio oportuno porque disfrazaba su españolidad, pues la tradicional mala imagen de los españoles en su opinión pública se había agravado durante la guerra de 1898 y sucesivas campañas propagandísticas de deslegitimación como antigua potencia colonial.

La prensa estadounidense había representado entonces a los españoles como un pueblo indolente, débil y poco civilizado, no sólo a través de la narrativa literaria, sino de iconografías y caricaturas como la que paradigmáticamente representaba a España como un torero decrépito, con barba blanca,

\footnotetext{
${ }^{7}$ Así lo adjetiva el Faro de Vigo (Fiesta artística, 1906, p. 2) al citarle como uno de los asistentes destacados a una fiesta ofrecida por Estanislao Durán.
} 
símbolo del pasado, viejo, decadente, sin capacidad para afrontar sus responsabilidades (Payne, 2003, p. 156). Este era un perfil común en la imagen de los españoles divulgada a lo largo del siglo XIX por historiadores como William Prescott, de gran influencia en la historiografía norteamericana, en contraste con los valores que la sociedad estadounidense se atribuía a sí misma (Boyd, 2002, p. 319).

Cuando se inició el reclutamiento de trabajadores inmigrantes en Cuba, los periódicos que publicaron informaciones sobre este hecho destacaron dos singularidades raciales de los gallegos: que poseían una identidad étnica diferente a la española y que su perfil físico y psicológico era idóneo para trabajar en el Canal de Panamá. Estos rasgos se pueden observar de modo arquetípico en una extensa crónica publicada por el New York Tribune el 25 de febrero de 1906, donde también se reflejan muchos de los tópicos negativos con los que los gallegos fueron estigmatizados en España. Sin embargo, este diario, propiedad del periodista, político republicano y negociador de la Paz de París, Whitelaw Reid (Barral-Martínez 2000, p. 630), consideraba a los trabajadores gallegos como apropiados para este proyecto: "they are well adapted to physical labor on the canal, (...) besides being strong and able to work hard and long under a hot sun, they are accustomed to going away from home to perform manual work”. (Gallegos at home, 1906, p. 2).

La mayor parte de esta crónica ${ }^{8}$, publicada en los siguientes 5 meses por 11 cabeceras, se ocupa de destacar sus características étnicas, presentándolos como la raza de campesinos más fuerte de España. Tras resaltar sus cualidades laborales y la necesidad de emigrar a causa de la pobreza, los describe como un pueblo amante de su tierra, próximo de los portugueses y distinto a los españoles por sus características culturales, tradiciones y lengua. Es decir, de forma implícita, se comunicaba que no compartían la estigmatización negativa del español, extendida tras la guerra hispanoestadounidense.

A pesar de situarlo en otra categoría diferente al español, el estereotipo social que esboza del gallego el New York Tribune es, en su mayor parte, una compilación de los clichés más negativos. Para exagerar su pobreza, recoge uno de los dichos despectivos que circulaban por la Península: "when they celebrate a wedding, feast on bread crusts". Y añade atributos propios de la literatura del Siglo de Oro, como se ha reseñado más atrás: "If the Gallego were only as clever as he is crafty, he would be well to do instead of a 'hewer of wood and a drawer of water'. Lacking in cleverness, he is an artful dodger." El New York Tribune señala incluso que no eran confiables y su palabra carecía de valor. Los calificaba como toscos, que tomaban la cortesía como signo de debilidad, por lo que, en la negociación de contratos, recomendaba intimidarles: "It is essential that one assume from the beginning that it will be necessary to browbeat him." Y en otro párrafo, para hacer más expresivo el carácter atribuido a los gallegos, hace una comparación con los bueyes y toros: "The people of Galicia have been likened to bullocks -heavy, plodding, occasionally vicious- without the charging courage of the bull." Esta crónica fue reproducida por once periódicos de ciudades del Sur, Medio Oeste y una de New Hampshire. Como era habitual en el periodismo de aquella época, en la crónica no se citaban fuentes y se recurría al "se dice" para sacar conclusiones, lo que lleva a pensar que la información pudo ser extraída de alguna enciclopedia, un libro de viajes o testimonios indirectos, quizás recogidos en Cuba.

\footnotetext{
${ }^{8}$ Esos periódicos fueron: Coffeyville Daily Record. (1906, 26 de marzo), p. 6. Spring Hill New Era. (1906 6 de abril), p. 1. The Louisburg Herald. (1906, 12 de abril), p. 4. The News-Herald. (1906, 12 de abril), p. 7. Westphalia Times (1906, 12 de abril), p. 4. The Dwight Tribune. (1906, 13 de abril), p. 5. The Portsmouth Herald (1906, 13 de abril), p. 3. The Leavenworth Times. (1906, 14 de abril), p. 5. Tazewell Republican (1906, 24 mayo), p. 3. The Holt County Sentinel. (1906, 22 de junio), p. 3; y Suburbanite Economist. (1906, 27 de junio), p. 8.
} 
Este retrato tan negativo de los gallegos no se refleja en los demás periódicos analizados, que ponen el acento en sus cualidades laborales para la construcción del canal y en sus diferencias étnicas con los demás españoles. The New York Times representaba a los gallegos con algunos valores similares a los propios de Estados Unidos, sobre todo en el norte (Boyd, 2002, p. 319), resaltando su sentido austero y el apego al trabajo: "[they] are notable all through those parts as laborers of industry, sobriety and hardiness ", . Además de laboriosos, también eran pragmáticos y nada supersticiosos, tal y como fueron representados por The Daily Telegram en un relato publicado y ambientado en Lisboa, uno de los destinos tradicionales de la emigración gallega en las primeras décadas del siglo XX (Twiss, 1907, p. 3).

Para la mentalidad norteamericana, estas cualidades podían no casar bien con el hecho de vivir en la pobreza hasta el punto de tener que cruzar un océano para conseguir un modesto trabajo de pico y pala. Esta contradicción la aclaraba The New York Times al apuntar su procedencia de montañas alejadas, marginados por los gobiernos españoles en el reparto del oro de las colonias americanas: "that once poured into the country had little or no effect upon them, for little or none of it was allowed to reach their mountains." Es decir, además de tener unas cualidades homologables a las de los obreros de Estados Unidos, se los representaba como víctimas de la España injusta que la llevó a la decadencia.

Este diario hace una defensa implícita de la decisión de la CCI de contratar inmigrantes gallegos para las obras del canal centroamericano. Tanto esta como otras publicaciones periódicas apelaban al marco mental presente entonces en el público lector estadounidense, que facilitaría poder establecer un cierto paralelismo entre los ciudadanos del norte de Estados Unidos y los originarios de Galicia, en defensa del trabajo libre como sinónimo de responsabilidad y apego a los derechos individuales frente al trabajo esclavo (Bender, 2011, p. 170). A los gallegos los situaba como los habitantes del norte, sin más precisiones: "the Spaniards of the north, or Gallegos, as they are commonly called from the name of their ancient kingdom". Y destacaba sus diferencias con los del sur de España: "they have a practicality sometimes missing in their brothers -or cousins, rather-of the southern parts of the peninsula."

Esta idea del norte donde se situaba la "raza superior", la blanca, frente al sur habitado por las supuestamente razas inferiores, formaba parte del ideario racista de la época, formulado por las ciencias sociales al incluir en su cuerpo doctrinal conceptos de la teoría de la evolución de las especies de Darwin (la llamada biologización de las ciencias sociales), y que obedecía a necesidades económicas y sociales de las sociedades occidentales en el momento de expansión imperialista (Hering-Torres, 2007, p. 25). Para aquellas mentalidades, las razas mejor dotadas, es decir, las más virtuosas para el desarrollo humano, se encontrarían más al norte, perdiendo pureza a medida que se bajaba hacia el sur (la latina). Fueron ideas que penetraron ampliamente en el imaginario social norteamericano (Reid-Merritt, 2018, p. 37). En este sentido, también varios autores latinoamericanos elaboraron una narrativa sobre la independencia del subcontinente y conformación de sus naciones en base a supuestos valores diferentes originarios de la ex metrópoli. Con frecuencia, opusieron un norte español virtuoso y altruista frente a un sur pobre y codicioso, asimilando los libertadores y criollos a una procedencia septentrional peninsular, y los conquistadores y opresores a la parte más meridional. Quizá el paradigma de esta visión racial latina sea la obra del polifacético escritor venezolano Arístides Rojas (Núñez-Seixas, 2017, p. 423).

\footnotetext{
${ }^{9}$ Similar descripción aparece publicada también en la crónica del The Star Press (Seeking Spaniards, 1906, p. 4), en la que se aseguraba que los gallegos eran de las pocas razas civilizadas que podían soportar la malaria y el calor tropical.
} 
Otros periódicos norteamericanos que publicaron noticias sobre el reclutamiento de trabajadores gallegos para las obras del canal adoptaron un discurso informativo parecido al del rotativo neoyorquino, centrado en describir la aptitud del obrero gallego para este trabajo y su procedencia del norte de España. Estos son los aspectos que ensalza LeRoy Park en unas declaraciones al The Washington Herald: "For centuries, these northern Spaniards have been renowned as working men. They are not of extra size, but muscular and strong and very excellent in sticking to their jobs" (At the hotels, 1907, p. 4). Particularidades que había subrayado un año antes el periodista y escritor John Foster-Carr en el semanario The Outlook al analizar la experiencia laboral con los gallegos llevados desde Cuba: "The best of all that have yet been tried are the Gallegos. There are life and spirit in their North Spanish blood" (Foster-Carr, 1906, p. 120). Es decir, además de trabajadores, los gallegos no compartían el supuesto espíritu débil y la vagancia con que la prensa norteamericana estereotipó a los españoles en la guerra de Cuba, utilizando las categorizaciones racistas de la época.

En la campaña para intentar tranquilizar a la opinión pública sobre las obras del canal tras la seria carencia de trabajadores de pico y pala efectivos, además de LeRoy Park, participaron cuadros medios e ingenieros, civiles y militares de la CCI junto a políticos republicanos. El teniente coronel Perkins se mostraba en el San Francisco Call satisfecho del rendimiento laboral de los operarios gallegos, augurando que se integrarían fácilmente en las cuadrillas de los "negros" (Thinks Panama..., 1907, p 3, 4). Afirmación con clara intención propagandística, pues era falsa, ya que los gallegos, como los demás españoles y europeos, pronto mostraron también una actitud racista, protestando, a veces con dureza, cuando se les exigía mezclarse en el transporte o en los comedores (Pérez, 2007, p. 156). Ello obligó a la CCI a tomar algunas medidas, como sustituir los policías negros caribeños que vigilaban los barracones dormitorio por agentes blancos (Goethals, 1915, p. 71). En definitiva, era la expresión racista de un enfrentamiento de fondo por el estatus racial, el trabajo y los sueldos, auspiciado, como ya se ha explicado, por la propia empresa constructora.

Esta rivalidad racial fue corroborada por el diputado John C. Chaney, tras la visita de una comisión del Congreso a las obras del canal. En una entrevista al The Washington Herald confió que una de las finalidades de la contratación de gallegos era estimular a los "indolentes" obreros negros del Caribe mediante la competencia laboral (At the hotels, 1907, p .6). Mientras, el ingeniero C. Alexander revelaba al The Burlington Free Press (Conditions in Panama, 1906, p. 4) que el buen sueldo que percibían (en relación con los antillanos) se debía a sus cualidades, como afirmaban también otros periódicos que los destacaban entre los mejores operarios manuales del canal (Wallace, 1910, p. 6). Una opinión que compartía el geógrafo inglés Vaughan Cornish (1909, p. 108), que consideraba a los gallegos tan resistentes como los italianos, calificados en Estados Unidos como los mejores trabajadores europeos.

Esta imagen de los inmigrantes gallegos circuló en la prensa norteamericana entre 1906 y el primer semestre de 1907, período de intenso reclutamiento de trabajadores para el canal. Posteriormente, salvo en algunos casos puntuales antes del final de las obras, los medios se refirieron a los españoles sin más concreciones étnicas o geográficas. Algunas circunstancias pueden haber influido en este cambio: la contratación se había extendido a todo el norte de la península, dejando los gallegos de ser casi los únicos procedentes de España. Para entonces la figura de ese extraño español, casi noespañol, trabajador, incansable y dócil había dejado de tener utilidad propagandística con la que tapar el fiasco de la contratación de obreros chinos, y la necesidad de operarios ya no era acuciante.

Las protestas, paros y motines, protagonizadas en la primavera de 1907 por los obreros españoles, sin distinción de procedencia regional, en demanda de mejores condiciones laborales, tampoco tuvieron cabida en las páginas de los periódicos norteamericanos al no estar ya los problemas laborales del canal en su agenda (Diebold, 2013, p. 16). A ello contribuyó la llegada en marzo de 1907 a la 
dirección de las obras del canal del coronel George Goethals, quien se rodeó de ingenieros militares, concentró y jerarquizó el poder al estilo castrense y, con la ayuda del periodista Joseph Buklin Bishop, controló la difusión de información sobre las obras en la Zona (López-Cerezo, 2014, p. 67).

\subsection{Creando nuevas percepciones. Campaña de imagen sobre las obras del Canal}

Las declaraciones recurrentes a los medios de comunicación de personas con responsabilidades en la construcción del paso interoceánico -con frecuencia ingenieros militares- parecen responder a la existencia de una campaña de propaganda planificada para mejorar la imagen del proyecto, que había sido puesto en cuestión por la prensa en 1905, motivando interpelaciones al gobierno en el Congreso. En este sentido, el eje de la operación mediática incluyó la difusión y elogio de las capacidades laborales de los gallegos como obreros no cualificados con fama de dóciles y esforzados operarios en Cuba. Son atributos distintos en apariencia a los recibidos por los inmigrantes gallegos en los destinos habituales de la emigración en Latinoamérica, pero no dejan de ser su reverso. La principal diferencia es que el término "gallego", además del inmigrante procedente de Galicia, para la prensa norteamericana significaba español del norte, un matiz étnico distintivo, no atribuible a todos los demás, como ya se ha señalado.

No hay datos que permitan medir el resultado de esta operación de imagen a favor de los obreros gallegos. Pero sí es reseñable la difusión general de informaciones con orientación favorable a la captación de inmigrantes gallegos, publicadas principalmente en periódicos de las áreas geográficas del noreste del país, el llamado Medio Oeste, California y, ocasionalmente, en algunos estados del sur. Es decir, los territorios más interesados en la futura vía marítima por su potencial para el desarrollo del comercio de estas zonas y porque, a través de sus representantes, habían apoyado la vía de Panamá en vez de Nicaragua. Esta era la opción de los antiguos estados sudistas, que la consideraban más adecuada a sus intereses (Díaz-Espino, 2004, p. 35).

La persona encargada de dirigir y monitorizar la imagen de la construcción del canal era Joseph Bucklin Bishop, periodista de confianza y amigo personal de Roosevelt (Missal, 2009, p. 58) ${ }^{10}$, quien en 1905 lo nombró secretario y responsable de comunicación de la CCI, en un momento en que arreciaban las críticas a la gestión del proyecto del Canal de Panamá. Bishop desempeñó inicialmente su trabajo desde Washington y, a partir de 1907, desde la Zona del Canal (Bishop, 2011, p. 27). Su cometido era mejorar la imagen de la obra y prevenir "false and the misleading reporting on the Canal" (Parker 2010, p. 80). En sus relaciones con los periódicos se apoyó en dos importantes herramientas: los informes de la CCI sobre la marcha de las obras y la creación de un semanario, The Canal Record, que desde 1907 se distribuyó masivamente.

De esta manera, Joseph Bishop logró desviar el centro de atención de los problemas laborales y técnicos hacia los avances de la construcción o los logros en la lucha contra la fiebre amarilla que diezmaba a los operarios (Sutter, 2016, p. 257), soslayando que la mayoría de las muertes se debían a neumonías e infecciones asociadas a las malas condiciones laborales y no a aquella dolencia tropical endémica (Sánchez, 2006, p. 86). Bishop consiguió suscitar en la prensa otros debates de distracción sobre aspectos como si la organización del trabajo y la convivencia de miles de personas para construir una mega obra constituía o no un modelo de estado en miniatura (Foster-Carr, 1906, pp. 435-445; asunto sobre el que opinaron diversos periodistas, que unas veces lo veían como un ejemplo de centralización, otras como una mancomunidad cooperativa o incluso como un ejemplo de un socialismo modificado que podía significar la materialización de algunas utopías sociales (Missal, 2009, p. 136).

\footnotetext{
${ }^{10}$ La amistad y colaboración era pública. (The Isthmian Canal, 1907, p. 1).
} 
La imagen de los gallegos como trabajadores eficientes volvió a ser noticia al finalizar las obras del canal, cuando autoridades y periodistas rememoraron las dificultades del proceso. Con ocasión de la exposición universal de San Francisco de 1915, el que había sido ingeniero jefe en la Zona del Canal, George Goethals, publicó una serie de artículos en los que exponía su punto de vista sobre las claves del éxito de su gestión. Entre otros aspectos, destacó las vicisitudes del manejo de la enorme masa laboral a lo largo de los siete años. A los obreros procedentes de Galicia los situó entre los mejores, destacando su resistencia y vigor, considerándolos inteligentes pero obedientes, restándole importancia a las protestas que protagonizaron junto a los demás españoles y europeos (Goethals, 1915, p. 71).

Varios escritores contribuyeron también a forjar ese estereotipo positivo. El aventurero y jefe de policía en la Zona del Canal, Harry Franck, que narró en un libro su experiencia en Panamá, rechazó la clasificación racista que situaba a los gallegos en una posición inferior (Franck, 1913, p. 27). Junto al resto de los españoles, Franck destacó su trabajo, honestidad y agudeza intelectual, "although 70 per cent of them arc wholly illiterate, and he finds them to be, almost universally, such honest, capable workers and upright citizens" (A Zone Policemen, 1913, p. 27). Un testimonio compartido por el hijo del responsable de la imagen pública de la construcción del canal, Farnham Bishop, quien recordó en el Boston Evening Transcript (An account in..., 1913, p. 15), que el reclutamiento de varios miles de campesinos de Galicia, fuertes y saludables, había sido un acierto para Estados Unidos. Mientras, el periodista del The Sun Rene Bache (1914, p. 11) contaba en una crónica que los gallegos "have show themselves to be very efficient" como obreros, y acompañaba el texto con un simbólico posado fotográfico de un grupo de "Galician workers" que transmitían seriedad, sobriedad y honestidad, tres de los rasgos más frecuentes reconocidos por la prensa de Estados Unidos.

El inicio de la Primera Guerra Mundial el 28 de julio de 1914, justo quince días antes de la inauguración del canal de Panamá, volvió a despertar en la opinión pública el interés por España, a causa de su posición de potencia neutral y a su situación geoestratégica (Páez-Camino 2014, p. 14). La prensa, además de analizar la política española en relación al conflicto bélico, volvió a apreciar simbólicamente la participación gallega en las obras del canal, posiblemente influida por la campaña de imagen para su contratación (The Workers at..., 1915, p. 48). Cuando ya el istmo panameño comenzaba a ser historia, en un amplio reportaje sobre la neutralidad de España firmado por el director editorial del relevante The Boston Globe, James Morgan (1915, p. 45), los obreros gallegos en Panamá vuelven a ser una vez más reconocidos. En una reflexión inspirada en las noticias publicadas por la prensa estadounidense durante las obras, Morgan concluye que "the Gallegos were among the most tireless diggers that the American engineers enlisted for the construction of the Panama Canal"11.

Gracias a estos comentarios elogiosos que respondían, esencialmente, a una estrategia mediática oportunista y coyuntural del gobierno de Estados Unidos, los toscos pero fuertes obreros gallegos pudieron alcanzar un cierto prestigio laboral en la esfera pública norteamericana y algunos círculos empresariales de Centroamérica; sin embargo, el estigma como inmigrantes rurales incultos, dóciles y esforzados trabajadores perduró en el imaginario colectivo como una marca indeleble de sus orígenes e idiosincrasia.

\section{Conclusiones}

\footnotetext{
${ }^{11}$ Este reportaje publicado íntegramente días después, el 26 de septiembre de 1915 por The Washington Herald, (p. 31) y Dayton Daily News, (p. 45).
} 
En el marco de la verificación de la hipótesis y en respuesta las preguntas específicas de investigación formuladas al inicio de este trabajo, se puede concluir lo siguiente:

1. Se confirma la hipótesis de que, frente a la cobertura de la prensa española, que centró su discurso en las pésimas condiciones de trabajo de los emigrantes, los periódicos norteamericanos realizaron una cobertura muy diferente, en la que los "gallegos" fueron objeto de una campaña de imagen que destacaba sus virtudes laborales por razones ideológicas y estratégicas. Se puede concluir, de forma general, que la imagen que ofrecieron los principales periódicos estadounidenses sobre los inmigrantes gallegos que trabajaron en el istmo fue positiva, tal y como demuestran los reportajes y crónicas analizadas del The New York Times, The Washington Herald, The Boston Globe o The Outlook.

2. Esta visión favorable de los "Gallegos" entra en contradicción con algunos estereotipos peyorativos que la prensa norteamericana había creado de los españoles, sobre todo a causa de la intensa propaganda antiespañola desplegada durante la guerra hispano-estadounidense de 1898. Entonces, España era vista como un país subdesarrollado y colonialista, cuya decadencia era la antítesis de la modernidad norteamericana, tanto desde el punto de vista tecnológico o económico, como en el contexto del desarrollo social y humano.

3. Es importante observar que el antiespañolismo norteamericano, trufado de clichés y prejuicios negativos sobre el carácter supuestamente indolente y atrasado de los españoles, estaba inspirado en un discurso racista que los situaba en una categoría inferior, por debajo de un ideal racial superior y de mentalidad emprendedora vinculado a los ciudadanos de Estados Unidos. El imaginario antiespañolista estaba esencialmente alimentado por un marcado sentimiento de deslegitimación hacia España como potencia colonial y modelo cultural para Hispanoamérica, en una clara pretensión por desplazar la influencia de España del continente americano y asumir una posición de liderazgo político y económico al tiempo que una progresiva preponderancia sociocultural desde el terreno del discurso simbólico y la representación mediática.

4. Respecto a la identidad de los inmigrantes gallegos, la prensa norteamericana estableció una curiosa diferenciación étnica en relación con los españoles. Esta imagen favorable de la prensa estadounidense hacia los inmigrantes gallegos del istmo panameño debe ser vista como una singularidad, sobre todo si se tiene en cuenta que los gallegos, tradicionalmente, habían sido objeto de una vulgarización estereotipada de su carácter, comportamiento y cualidades, asociados a una escasa socialización, analfabetismo y su procedencia rural, portando un estigma negativo que se extendió a los destinos de la emigración gallega en América. La caracterización amable y diferenciada de la prensa estadounidense hacia los obreros gallegos, debe ser interpretada como una estrategia propagandística y oportunista en el contexto de la propia gestión que las autoridades estadounidenses hicieron de la construcción del canal de Panamá.

5. La imagen virtuosa que se difundió de los trabajadores gallegos debe encuadrarse en la campaña de imagen que impulsó el gobierno de Estados Unidos desde mediados de 1905, tras su fracaso durante el primer año y medio de gestión en las obras del istmo. Para cambiar la percepción negativa de la opinión pública de su país, el presidente Theodore Roosevelt intentó crear un clima de opinión favorable al desarrollo del proyecto. La imposibilidad política de contratar a obreros asiáticos motivó el reclutamiento de centenares de inmigrantes gallegos en Cuba y, posteriormente, en Galicia, cuyo resultado fue satisfactorio. Sin embargo, para desvincularlos de su negativo origen español, la CCI decidió afirmar y publicitar su identidad gallega.

6. En relación con el perfil étnico de los inmigrantes gallegos, es relevante destacar la categoría que algunos medios utilizaron para referirse a ellos como "North Spanish blood". Este encuadre obedeció, en el marco del imaginario racista de la época, que situaba a las razas "virtuosas" en el norte, a una intención de diferenciar a los gallegos ("españoles del norte") del estereotipo negativo de los españoles, existente en Estados Unidos. La mayoría de las cabeceras analizadas incidieron en sus diferencias étnicas con los demás españoles, descalificados generalmente como 
decadentes y perezosos, mientras los gallegos eran vistos como trabajadores fuertes, manejables y con suficiente inteligencia.

7. La representación del arquetipo étnico de los gallegos se acentuó en dos momentos concretos de la construcción del canal. El primero, entre enero de 1906 y mediados de 1907, período de intensa necesidad de contratación de operarios en el que la prensa los describe como excelentes e incansables trabajadores. Y el segundo, en el tramo final de las obras y con ocasión de la feria San Francisco de 1915, cuando la prensa rememoró el trabajo útil y eficiente de los gallegos, cuya imagen seguiría aun proyectándose con ese mismo tono laudatorio en libros publicados entonces y en años posteriores.

8. Esta representación positiva centrada en su valía laboral, aunque en apariencia diferente, guarda relación con muchos de los estereotipos negativos construidos sobre los gallegos en los países latinoamericanos a donde emigraron masivamente. Sin embargo, paradójicamente, a pesar de su marcado perfil étnico en la prensa estadounidense y de ser el contingente mayoritario entre los obreros españoles de la Zona del Canal, los trabajadores gallegos prefirieron mantener una identidad fluida o binaria, inclinándose generalmente por asumir su nacionalidad española, motivados sobre todo por la política racial del gobierno norteamericano hacia la masa laboral, que relegaba a todos los peninsulares y, en general, a los europeos a una posición subordinada frente a los blancos de Estados Unidos.

\section{Referencias}

32.000 on canal pay roll. (1910, 12 de enero). The Miami News, p. 1.

A Zone Policemen (1913, 27 de abril). The New York Times, p. 27.

Alonso, B. (2013). Constructores de imperios (Traballadores galegos nos Estados Unidos e no canal de Panamá entre $1900 \quad$ e https://issuu.com/bieitoalonso/docs/construtores_de_imperios_1_/103

Alonso-Montero, X. (1974) Galicia vista por los no gallegos. Editorial Júcar.

An account in the Isthmus: past and present. (1913, 8 de febrero). Boston Evening Transcript, p.16.

Araúz, C. y Pizzurno, P. (2003). La construcción del Canal de Panamá, 1904-1914. Mesoamérica, 24(45), 100-130.

Ardèvol-Abreu, A. (2015). Framing o teoría del encuadre en comunicación. Orígenes, desarrollo y panorama actual en España. Revista Latina de Comunicación Social, 70, 423-450. http://www.revistalatinacs.org/070/paper/1053/23es.html Doi: https://dx.doi.org/10.4185/RLCS$\underline{2015-1053}$

At the hotels. (1907, 13 de mayo). The Washington Herald, p. 4.

At the hotels. (1907, 27 de marzo). The Washington Herald, p. 6.

Bache, R. (1914, 1 de febrero). Busines of the completed canal. The Sun, p. 11. 
Baqués-Quesada, J. (2018). Las lecciones fundamentales de la obra de Mahan: del determinismo geográfico al espíritu comercial. Revista del Instituto Español de Estudios Estratégicos, 11, 107130. https://revista.ieee.es/article/view/166

Barral-Martínez, M. (2000). Eugenio Montero Ríos y el Tratado de París. En: D. Kremer (Ed.), Un século de estudios galegos, Galicia fóra de Galicia: actas do VI Congreso Internacional de Estudios Galegos (621-635). Ediciós do Castro-Universidad de La Habana, Cátedra de Cultura Gallega.

Barrientos-Báez, A, Barquero Cabrero, M. y García García, E. (2018). Posverdad y comunicación 2.0: el reto periodístico de una era sin periodistas. Revista de Ciencias de la Comunicación e Información, 23(1), 43-52. http://doi.org/10.35742/rcci.2018.23(1).43-52

Bender, T. (2011). Historia de los Estados Unidos: una nación entre naciones. Siglo Veintiuno.

Beramendi, J. (2002). Identidad, etnicidad y estado en España: Siglos XIX y XX. En: W. Safran y R. Máiz (Coords.), Identidad y autogobierno en sociedades multiculturales (113-136). Ariel.

Bigelow, B. (1906, 1 de abril). Facts about conditions in Panama. The Washington Post, p. 10.

Bishop, Ch. (2011). Lion and the Journalist: The Unlikely Friendship of Theodore Roosevelt and Joseph Bucklin Bishop. Rowman y Littlefield.

Boyd, C.P. (2002). La imagen de España y de los españoles en Estados Unidos de América. Investigaciones históricas: Época moderna y contemporánea, 22, 317-328.

Checa Calderón, V. y Rodríguez Caguana, T. (2017). Análisis del liderazgo y su relación con la motivación laboral en S.E.R.L.I. Sociedad Pro-Rehabilitación en Guayaquil en el año 2016. Revista de Comunicación de la SEECI, 44, 155-170. http://dx.doi.org/10.15198/seeci.2017.44.155-170

Chou, D. (2002). Los chinos en Hispanoamérica. FLACSO.

Conditions in Panama. (1906, 20 de julio). The Burlington Free Press, p. 4.

Cornish, V. (1909). The Panama Canal and its Makers. T. Fisher Unwin.

Cuadriello, J. (2014). Españoles en Cuba en el siglo XX. Editorial Renacimiento.

De Guzmán, M. (2005). Spain's Long Shadow. The Black Legend, Off-Whiteness, and AngloAmerican Empire. University of Minnesota Press.

Díaz Espino, O. (2004). El país creado por Wall Street: la historia prohibida de Panamá y su canal. Destino

Diebold, P.C. (2013). Labor Issues During the Construction of the Panama Canal, Young Historians Conference. Paper 2. http://pdxscholar.library.pdx.edu/younghistorians/2013/oralpres/2 
Farías, R. (2010). Viejos estereotipos y nuevos discursos: la visión de Galicia y de los gallegos en una fracción de la élite galaico-porteña a mediados de la década de 1940. Madrygal. Revista de Estudios Gallegos, (13), 51-61. https://dx.doi.org/10.5209/MADR

Feldstein, M. (2006). A muckraking model: Investigative reporting cycles in American History. Harvard International Journal of Press/Politics, $11(2), \quad 105-120$. https://doi.org/10.1177/1081180X06286780

Fiesta Artística. (1906,10 de agosto), p. 2.

Formoso, D. y Pena Rodríguez, A. (2018). Los obreros españoles en la construcción del canal de Panamá: su imagen en la prensa española (1906-1909). Historia Crítica, (67), 23-44. https://doi.org/10.7440/histcrit67.2018.02

Foster-Carr, J. (1906, 23 de junio). The Panama Canal: Building a State. The Outlook, pp. 435-445.

Foster-Carr, J. 1906, 19 de mayo). The Panama Canal: the silver men. The Outlook, p. 120.

Franck, H.A. (1913): Zone policeman 88: a close-range study of the Panama Canal and its workers. The Century Co.

Gallegos at home. (1906, 25 de febrero). New York Tribune, pp. 2 y 8.

Goethals, G. (1915, 9 de mayo). Col. Goethals Own story of building the Panama Canal. St. Louis Post-Dispatch, p. 71.

González-Suárez, D. (2005). Los españoles en Cuba: Conflictos y Estereotipos. ASCE Proceedings, (15), 205-220. https://econpapers.repec.org/article/qbaannpro/v_3a15_3ay_3a2005_3aid_3a613.htm

Greene, J. (2004). Spaniards on the Silver roll: Labor troubles and Liminality in the Panama Canal Zone, 1904-1914. International Labor and Working-Class History 66, 78-98. https://doi.org/10.1017/S0147547904000183

Greene, J. (2011). Los constructores del canal. Radom House Mondadori.

Guerrero, L. y Lorente, J. (1908). Los obreros españoles en panamá. Informe. Rambla y Bouza.

Guidotti, M.; Lojo, M.R. y Farías, R. (2008). Los "gallegos” en el imaginario argentino: literatura, sainete, prensa. Fundación Pedro Barrié de la Maza.

Hering Torres, M. (2007). 'Raza': variables históricas. Revista de Estudios Sociales, 26, 16-27. https://doi.org/10.7440/res26.2007.01

Iglesias-Cruz J. (2012). Galicia y los gallegos en la política cubana. En: O. Rodríguez González, P. Carballo y B Baltrucsh (Eds.), Novas achegas ao estudo da cultura galega II: enfoques sociohistóricos e lingüístico-literarios (363-374). Servizo de Publicacións da Universidade de A Coruña. 
Kramer, J. (1997). La imagen de Galicia y del gallego en las enciclopedias alemanas. En: D. Kremer (Ed.), Actas do V Congreso Internacional de Estudios Galegos: Universidade de Tréveris 8-11 de outubro de 1997 (151-158). Ediciós do Castro.

Llevot Cavet, N. y López Teulón M. P. (2017). Asociaciones africanas en Cataluña: fortalezas y debilidades. Vivat Academia, Revista de Comunicación. 141, 55-68. http://doi.org/10.15178/va.2017.141.55-68

Lojo, M.R. (2016) La Argentina y su criptoidentidad gallega. Olivar, vol. 17(25), sin paginación. https://www.olivar.fahce.unlp.edu.ar/article/view/OLIe002.

López-Cerezo, J. A. (2014). El canal de Panamá: una perspectiva histórica y social. Los Libros de la Catarata.

Los esclavos modernos. (1907, s/f). Madrid Científico, (569), p. 1.

Mack, G. (1978). La tierra dividida -Historia del Canal de Panamá y otros proyectos del Canal ístmico. Editorial Universitaria.

Magoon, Ch. (1907, 12 de diciembre). Carta a G. Goethal sobre quejas de los emigrantes a sus familiares. Records of the Panama Canal, 1904-1960, File 2-E-6/Spain, R.G. 185. NARA.

Máiz, R. (2003). La construcción mediática de la nación. Marcos interpretativos identitarios en la prensa gallega. En: V. Sampedro (Ed.), La pantalla de las identidades: Medios de comunicación, políticas y mercados de identidad (105-124). Icaria Editorial.

Marco-Serra, Y. (2012). Son blancos, manejables, y capaces de desarrollarse e integrarse: obreros españoles en el canal de Panamá, 1904-1914. Tiempos de América: Revista de historia, cultura y territorio, 19, 71-88.

Marcos Ramos, M., González de Garay, B. y Portillo Delgado, C. (2019). La representación de la inmigración en la ficción serial española contemporánea de prime time. Revista Latina de Comunicación Social, 74, 285-307. http://doi.org/10.4185/RLCS-2019-1331

Martínez O’Farrill, L. M. (2019). El color de la piel un factor de discriminación en la educación $\begin{array}{lllll}\text { cubana. Revista de } \text { Comunicación } & \text { y } & \text { Salud, } & 9(1), & \text { 39-49. }\end{array}$ http://doi.org/10.35669/revistadecomunicacionysalud.2019.9(1).39-49

Martínez O'Farrill, L. (2018). El racismo un problema cultural que puede ser reeducado. Revista de $\begin{array}{llrrr}\text { Comunicación } & y & \text { Salud, } & 8(2), & \text { 65-76. }\end{array}$ http://doi.org/10.35669/revistadecomunicacionysalud.2018.8(2).65-76

Missal, A. (2009). Seaway to the Future: American Social Visions and the Construction of the Panama Canal. https://uwpress.wisc.edu/books/4492.htm

Montero-Ríos, E. (1906, 12 de julio). Carta al presidente del gobierno J. L. Domínguez. Records of the Panama Canal, 1904-1960, File 2-E-2/Spain, R.G. 185, NARA.

Morgan, J. (1915, 12 de septiembre). Spain neutral for the first time. The Boston Globe, p. 45. 
Moya, J. C. (1998). Cousings and Strangers. Spanish Immigrants in Buenos Aires, 1850-1930. University of California Press.

Moya, J. C. (2008). Tanos e Gaitas: inmigración, asentamento e competencia simbólica dos italianos e españois en Arxentina. Estudos Migratorios, 1(1), 49-79.

Moya, J. C. y Mckeon, A. (2011). World Migration in the Long Twentieth Century. En: M. Adas (Ed.), Essays on Twentieth Century History (9-53). Temple University Press.

Murado, M. A. (2008). Otra idea de Galicia. Debate.

Navas, L. (1979). El movimiento obrero en Panamá (1880-1914). Editorial Universitaria Centroamericana.

Niño González, J. I. y Linares Herrera, M. P. (2020). Investigar: Acción impostergable. Bibliotecas. Anales de Investigación, 16(1), 5-6. www.bnjm.cu/revista-anales/index.php

Núñez-Seixas, X. M. (2013). Icônes littéraires et stéréotypes sociaux: l'image des immigrants galiciens em Argentine (1800-1960). Presses Universitaires de Franche-Comté.

Núñez-Seixas, X. M. (2015). Las patrias ausentes: Estudios sobre historia y memoria de las migraciones ibéricas (1850-1960). Genueve.

Núñez-Seixas, X. M. (2017). ¿Negar o reescribir la hispanidad? Los nacionalismos subestatales ibéricos y América Latina, 1898-1936. Historia mexicana, 67(1). 401-458. http://dx.doi.org/10.24201/hm.v67i1.3447

Páez-Camino, F. (2014) España ante la Primera Guerra Mundial. Universidad de Mayores de Experiencia Recíproca.

Park, L. (1906, 14 de noviembre) Carta a J. Smith. Records of the Panama Canal, 1904-1960, File 2E-2/Spain, R.G. 185. NARA.

Park, L. (1906, 17 de septiembre). Memorando a J. Smith. Records of the Panama Canal, 19041960, File2-E-2/Spain. R.G. 185. National Archives and Records Administration (NARA).

Parker, M. (2010). La fiebre de Panamá. La lucha por construir el canal. Random House Digital.

Payne, S. (2003). Los Estados Unidos y España: percepciones, imágenes e Intereses. Cuadernos de Historia Contemporánea, 25, 155-167.

Pérez, J.M. (2007). Pro mundi beneficio: los trabajadores gallegos en la construcción del Canal de Panamá, 1904-1914. Fundación Pedro Barrié de la Maza.

Procter, B. (1998). William Randolph Hearst: The Early Years, 1863-1910. Oxford University Press.

Reid-Merritt, P. (Ed.) (2018). A State-by-State History of Race and Racism in the United States. (vol.1). Greenwood.

Repatriating laborers (1914, 28 de octubre). The Canal Record, p. 3 
Rodrigo-Alsina, M. y Medina, P. (2009). Los medios de comunicación en contextos interculturales. Sociedad y Discurso, (16), pp. 21-39.

Roediger, D. R. y Esch, E.D. (2012). The production of difference: race and the management of labor in US history. Oxford University Press.

Rothbard, M. N. (1996). Origins of the Welfare State in America. Journal of Libertarian Studies, 12(2), 193-232.

Sánchez, G. B. (2006) El Canal de Panamá y sus vidas. Vidas y muertes durante el período de construcción del Canal de Panamá (1904-1914). Hats of Books.

Sánchez-Cobos, A. (2008). Sembrando Ideales: anarquistas españoles en Cuba, 1902-1925. CSIC.

Sandrad, E. (1907, febrero-marzo). Informes sobre la huida de trabajadores de la Zona del Canal. Records of the Panama Canal, 1904-1960, File 2-E-3/Spain, R. G. 185. NARA.

Santacruz Espinoza, A., Montenegro Muguerza, H., Pizarro Alejandro, A. y Estacio Flores, H. (2020). Liderazgo transformacional y desarrollo sostenible ambiental verde en docentes de la Universidad Nacional HerminioValdizán. Revista de Comunicación de la SEECI, 53, 135-151. https://doi.org/10.15198/seeci.2020.53.135-151

Seeking Spaniards. (1906, 6 de febrero). The Star Press, p. 4,

Shaffer, K. R. (2011). Contesting internationalists: Transnational anarchism, anti-imperialism and US expansion in the Caribbean, 1890s-1920s. Estudios Interdisciplinarios de América Latina y el Caribe, 22(2), 11-38. http://eial.tau.ac.il/index.php/eial/article/view/283

Shonts broke pledge on Chinese Gompers (1906, 12 de Agosto). The New York Times, p. 4.

Shonts, T. (1915). The railroad Panamá.” En: I. E. Bennett (Ed.), History of the Panama Canal: its construction and builders (pp. 202-209). Historical Publishing Company.

Soto Lara, J., Chávez Zúñiga, P. y Dallmann, J. (2019). Inmigrantes del Perú en la prensa de Chile: El caso de "La Estrella" de Arica (2000-2010). Historia y Comunicación Social, 24(2), 649-664. https://doi.org/10.5209/hics.66306

Stevens, J. (1915). "The true of history". En: I. E. Bennett (Ed.), History of the Panama Canal: its construction and builders (210-224). Historical Publishing Company.

Sutter, P.S. (2016). 'The First Mountain to Be Removed': Yellow Fever Control and the Construction of the Panama Canal. Environmental History, 21(2), 250-259. https://doi.org/10.1093/envhis/emv165

Teijeiro-Fuentes, M. A. (1996). Galicia y los gallegos en la literatura española del Siglo de Oro. Scriptura (11), 203-246.

The Isthmian Canal. (1907, 26 de junio). The National Tribune, p. 1. 
The Workers at Panamá. (1915, 7 de abril). The Pittsburgh Press, p. 48.

Thinks Panama Canal will be finished in seven years. (1907, 8 de julio). San Francisco Call, p. 3.

Twiss, R. (1907, 2 de enero). A Gallego’s Shelter. The Daily Telegram, p. 3.

Vaquerizo Domínguez, E. (2019). Medios étnicos, adaptación al ecosistema digital y usos de la diáspora migrante. Vivat Academia, Revista de Comunicación. 149, 127-151. http://doi.org/10.15178/va.2019.149.127-151

Varela-Lago, A. M. (2008). Conquerors, immigrants, exiles: the Spanish diaspora in the United States (1848-1948) (Tesis doctoral, UC San Diego). UC San Diego Electronic Theses and Dissertations. https://escholarship.org/uc/item/4m7181hk

Vidal-Rodríguez, J. A. (2003). La inmigración española en Cuba durante la primera ocupación militar norteamericana (1899-1902): El control del mercado laboral. En: Migraciones y Exilios: Cuadernos de la Asociación para el Estudio de los Exilios y Migraciones Ibéricos Contemporáneos, 4, 31-49.

Vidal-Rodríguez, J. A. (2005). La emigración gallega a Cuba: trayectos migratorios, inserción y movilidad laboral, 1898-1968. CSIC.

Wagenknecht, E. (1982). American Profile, 1900-1909. University of Massachusetts Press.

Wallace, A. (1910, 10 de enero). Wasington Gosip. The St. Louis Star and Times, p. 6.

Walls Ramírez, M. (2020). Aportes de la comunicación para la difusión del patrimonio cultural. Revista de Ciencias de la Comunicación e Información, 25(1), 49-55. http://doi.org/10.35742/rcci.2020.25(1).49-55

\section{AUTORES}

\section{Alberto Pena-Rodríguez}

Alberto Pena-Rodríguez es doctor (con Mención Europea) en Ciencias de la Información por la Universidad Complutense de Madrid, en Historia por la UNED y profesor titular de Historia de la Propaganda en la Universidad de Vigo. Entre otras universidades, ha sido profesor o investigador visitante en Harvard University, University of California Berkeley, Brown University y University of Massachusetts Dartmouth. Entre sus últimas publicaciones, están News on the American dream. A history of the Portuguese press in United States (University of Massachusetts Press, en prensa) y Salazar y Franco. La alianza del fascismo ibérico contra la España republicana: diplomacia, prensa y propaganda (Ediciones Trea, 2017).

alberto@uvigo.es

ORCID ID: $\underline{\text { https://orcid.org/0000-0001-8667-6287 }}$

GoogleScholar: https://scholar.google.com/citations?user=jGDGCgsAAAAJ\&hl=es

\section{David Formoso-Vázquez}

David Formoso-Vázquez es periodista y profesor asociado en la Universidad de Vigo por la que es doctor en ciencias sociales. Su línea principal de investigación es la historia de la comunicación a la que responden sus artículos La representación en la prensa española del discurso del presidente 
RLCS, Revista Latina de Comunicación Social, 79, 89-111

[Investigación] DOI: 10.4185/RLCS-2021-1490| ISSN 1138-5820| Año 2021

Theodore Roosevelt en defensa de la construcción del canal de Panamá o Los obreros españoles en la construcción del canal de Panamá: su imagen en la prensa española (1906-1909). Como periodista desempeñó esta profesión durante 27 años en RTVE, de los cuales 17 desempeñó diversos cargos de responsabilidad en Galicia. Trabajó también en El País, La Voz de Galicia y El Correo Gallego. Es premio "Mestre Mateo" por el documental Man, home sen paz.

davidformoso@uvigo.es

ORCID ID: https://orcid.org/0000-0002-5757-0392

GoogleScholar: https://scholar.google.es/citations?hl=es\&user=pukNMaAAAAAJ 